\title{
Study on feed fermented from seaweed waste
}

\author{
Shuping Zhang ${ }^{1 \star}$, Xiaojian $\mathrm{Hu}^{2}$, Jie Ma ${ }^{1}$, Zhengqiang $\mathrm{Ma}^{3}$, Xiaohui $\mathrm{Liu}^{2}$ and Lei Cui ${ }^{1 *}$ \\ ${ }^{1}$ College of Science, University of Shanghai for Science and Technology, Shanghai, China. \\ ${ }^{2}$ School of Environment and Architecture, University of Shanghai for Science and Technology, Shanghai, China. \\ ${ }^{3}$ Kashi Agricultural Center, Xinjiang, China. \\ Accepted 5 December, 2012
}

\begin{abstract}
This paper focuses on several factors on the effect of fermented feed from seaweed waste. The fermentation process is optimized through nutritional analysis. The study which compared the crude protein and the crude fiber resulted to an increase by $34.56 \%$ and decreased by $10.72 \%$, respectively in seaweed feed. The findings of this study suggest that the best feed could be fermented from seaweed waste while adding $1 \%$ of microbial agents and $0.5 \%$ of corn powder, fermenting for 15 days.
\end{abstract}

Key words: Seaweed waste, fermentation, feed.

\section{INTRODUCTION}

Seaweed is the most widely distributed organisms in the ocean. It is a lower cryptogam growing in the ocean, rich in protein, amino acid, inorganic salt, vitamin, alginate, a small amount of enzyme, plant hormones, polyphenols and polysaccharides (Gao et al., 2004). At present, there are abundant seaweed resources in China, but the industrial utilization of seaweed is low.

Usually, the seaweed waste is treated as chemical solid waste after extraction of alginate, iodine and mannitol. There are many problems in existing disposal ways, such as the small utilization scale and the high utilization cost. Thus, it has caused environmental pollution and waste of resources. Results show that seaweed waste respectively contains about $20 \%$ crude protein, $50 \%$ crude fiber and $3 \%$ ash content (Gan et al., 1999). Only parts of seaweed waste are used for organic fertilizer, most of them are discharged as waste, eventually leading to environmental pollution and waste of resources. Seaweed waste contains iodine, vitamins, minerals, dietary fiber and active ingredient. These nutrient elements are mostly organic form, which are not prone to oxidation in the natural environment and can be preserved in seaweed waste as animal feed. In addition, the seaweed waste has high practical value, non-toxic

\footnotetext{
*Corresponding author. E-mail: zhang_lucy9999@yahoo.com.cn. Tel: +86 13371935893.

Fax: +86 2155270957 .
}

and harmless to animals. At the same time, it has some medicinal value, such as; reduces the animal morbidity, increases growth rate and improves the quality (Cheng et al., 2003).

At present, some achievements have been made about feed fermenting by seaweed waste in domestic, the seaweed waste is widely used in poultry feed, especially as aquatic feed. The results show that in broiler feeding comparative tests, the rate of weight gain of broilers was significantly increased in the experimental group. The production of the egg in the experimental group was significantly higher than the control group; the iodine content in the egg yolk (fresh) was increased from 914 to $6618 \mathrm{ug} / \mathrm{g}$, which can improve the quality of the eggs. After feeding seaweed waste fermented feed, the growth of the pigs were obviously promoted resulting to fattening pigs and regulation of gastrointestinal function, so as to reduce the material consumption and increase income (Wang et al., 2009). In the experiment of feeding tilapia with seaweed waste, when the seaweed was added less than $30 \%$, the experimental group totals' amino acid digestibility increased slightly. Seaweed waste contains a large number of required amino acids such as lysine and methionine; proper amount of seaweed in fish feed can supply and adjust the growth of fish needed amino acid, reduce the content of heavy metals in fish muscle, promote the growth of fish and improve its quality (Gan et al., 1999). Table 3 shows that the seaweed feed contains more than 12 types of vitamins, a variety of water-soluble and fat-soluble vitamins (including vitamin $\mathrm{C}$ and $\mathrm{E}$ ). 
Mineral content was also very abundant; these minerals were in natural chelated form, easy to be absorbed by animals. Seaweed feed protein content is not high, but contains large amounts of free amino acids, such as alanine, glycine and glutamic acid ( $\mathrm{Li}$ et al., 2007). Therefore, seaweed waste fermented feed has the following advantages. Firstly, seaweed waste fermented feed can improve the quality of the feed and reduce the cost of feeding and processing. Secondly, it can meet the nutritional needs of livestock and poultry feed nutrition which tends to be more scientific, reasonable and comprehensive. Thirdly, seaweed waste fermented feed is effective in preventing the occurrence of animal diseases, livestock and poultry products with high quality, high efficiency, low consump-tion, obtaining greater value-added products and the best economic benefit (Zeng et al,. 2004). The feed fermented from seaweed waste is a new type of green feed characterized by nonpolluting. The application of sea-weed waste will solve the energy shortage problem.

This paper mainly study on several factors about the effect of fermented feed from seaweed waste. In the experiments, the main technology is microbial fermentation; the experimental method is based on single factor. Therefore, it can also provide a reference for further development and application on seaweed waste.

\section{MATERIALS AND METHODS}

\section{Materials}

Seaweed waste was gotten from the seaweed industry such as algin, mannitol, iodine, fucoidan and other products. It was shattered into piece for particle size of 1 to $5 \mathrm{~mm}$ before fermentation. Microbial agents and corn powder were both bought from the market. The potassium dihydrogen phosphate was an analytical reagent.

\section{Methods}

\section{Sample fermentation}

Firstly the microbial agents was put into the glucose solution whose concentration was $<1 \%$, and kept for four hours at normal temperature. Secondly, $50 \%$ of dry seaweed waste and $5 \%$ of potassium dihydrogen phosphate was mixed (Zhang et al., 2000) with and other adjuvants. The solution was equably sprinkled to the mixture. The $\mathrm{pH}$ of the mixture was adjusted from 4.5 to 6.0. The water content was $70 \%$, and the feed could form uniform and small particle. Thirdly, they were placed in a sealed bucket for anaerobic fermentation at a temperature of 25 to $30^{\circ} \mathrm{C}$. Finally, the fermentative products were dried at the natural temperature or at the temperature of $65^{\circ} \mathrm{C}$ in the blast drier and shattered (Yang et al., 2005) as shown in Figure 3.

\section{Storage of sample}

Samples which were reduced to $500 \mathrm{~g}$ through method of quartering were dried and shattered to 40 yards. Then they were narrowed 200 $\mathrm{g}$ through the same method and placed into sealed containers in a cool and dry place.

\section{Quality identification}

a) Field assessment: The samples were evaluated on color, smell and quality after opening the sealed containers (Liu et al., 1999).

b) Laboratory assessment: The method of determination of $\mathrm{pH}$ was to measure the supernatant which was made up to $20 \mathrm{~g}$ of seaweed feed and $30 \mathrm{~mL}$ of water kept for five minutes with PHS-3 C precision acidity meter (Yang, 1993).

c) Determination of conventional nutrients was on the basis of national standards, the determination of related substances: determination of crude protein (CP) was referred to as GB/T 643294; crude fiber (CF) as GB/T 6434-94; ether extract (EE) as GB/T 6433-94; ash as GB/T 6438-92 and determination of moisture as GB/T 6435-86.

\section{RESULTS AND DISCUSSION}

The previously mentioned methods were used to determine the nutrients of different fermentation factors such as $\mathrm{CP}, \mathrm{CF}, \mathrm{EE}$, ash, moisture and nitrogen free extract (NFE).

\section{Results}

Table 1 shows the different fermentation method with different microbial agents added as well as fermentation time and corn powder added. Other factors did not change except the three factors mentioned previously. The temperature was $25^{\circ} \mathrm{C}$ and water content was 70 ( $\mathrm{Yu}$, 2006). In addition, it costed four hours to make microbial agents activated. Seaweed waste materials, water and potassium dihydrogen phosphate were respectively 1000 , 1500 and $5 \mathrm{~g}$. Table 2 shows the nutrients of seaweed feed in different fermentation process.

\section{Analysis of results}

\section{Sensory effects}

The seaweed waste unprocessed was coarse and drier. By contrast, the feed fermented by seaweed felt softer, sound mellower and was brown.

\section{Analysis of nutrients}

It could be found in these experiments that crude protein of seaweed feed significantly increased and crude fiber of them decreased. In other words, the crude fiber digested difficultly was gradated into the nutrients easily digested and digestive protein increased at the same time, which effectively improved the palatability of seaweed as feed.

a) The relationship between the time and fermentation effect: Figure 1 shows the relationships between the time 
Table 1. Different fermentation parameter for the experimental program.

\begin{tabular}{lccc}
\hline Parameter & Microbial agent (\%) & Time (Day) & Corn powder (\%) \\
\hline 1 & 0 & 15 & 0 \\
2 & 0.5 & 15 & 0 \\
3 & 1 & 5 & 0 \\
4 & 1 & 7 & 0 \\
5 & 1 & 10 & 0 \\
6 & 1 & 15 & 0 \\
7 & 1 & 20 & 0 \\
8 & 1.5 & 15 & 0 \\
9 & 2 & 15 & 0 \\
10 & 1 & 15 & 0.5 \\
11 & 1 & 15 & 1 \\
\hline
\end{tabular}

Table 2. The nutrients of seaweed feed in different fermentation process.

\begin{tabular}{lcccccc}
\hline Parameter & Moisture (\%) & CP (\%) & EE (\%) & Ash (\%) & CF (\%) & NFE (\%) \\
\hline 1 & 11.37 & 10.52 & 0.54 & 21.06 & 8.89 & 47.62 \\
2 & 10.53 & 11.98 & 0.41 & 20.34 & 8.49 & 48.48 \\
3 & 9.22 & 12.24 & 0.48 & 20.06 & 8.54 & 49.46 \\
4 & 9.43 & 12.56 & 0.40 & 20.40 & 8.31 & 48.9 \\
5 & 9.74 & 12.83 & 0.39 & 20.43 & 8.07 & 48.54 \\
6 & 10.06 & 13.13 & 0.37 & 20.57 & 7.85 & 48.02 \\
7 & 9.84 & 13.02 & 0.40 & 20.69 & 7.78 & 48.27 \\
8 & 10.49 & 12.87 & 0.40 & 21.04 & 8.59 & 46.25 \\
9 & 10.75 & 12.52 & 0.47 & 21.76 & 8.03 & 46.47 \\
10 & 9.26 & 13.92 & 0.39 & 23.53 & 8.19 & 44.71 \\
11 & 9.58 & 13.95 & 0.41 & 22.81 & 7.99 & 45.26 \\
Seaweed waste & 10.44 & 10.36 & 0.49 & 24.91 & 8.95 & 45.21 \\
\hline
\end{tabular}

$\mathrm{CP}$, Crude protein; EE, ether extract; CF, crude fiber; NFE, nitrogen free extract.

and fermentation effect of three to seven processes. It also descripted that the crude protein had an increasing trend and the crude gradually decreased with the fermentation time before the fifteenth day, which signifies that fermentation effect was proportional to the fermentation time. In addition, the content of crude protein was highest for the fifteenth day and decreased thereafter. Because the microorganisms in microbial agents were in a decline phase and the number of them began decreasing. Furthermore, nutrients had been insufficient to maintain microorganisms to survive so that microorganisms (Lu et al., 2010) consumed the nutrients in seaweed feed. In conclusion, fifteen days was the most favorable for fermentation.

b) The relationship between the microbial agents added and fermentation effect: Figure 2 shows the relationship between the microbial agents added and fermentation effect of processes 1, 2, 8 and 9. The content of crude protein was the most when the microbial agents were added by one percent. However, it was lower when the content of microbial agents was less than or more than one percent. It was because that the seaweed waste could not be fully decomposed by microorganisms with little agents, too many microbial agents competing each other was not conductive to fermentation of seaweed waste. In conclusion, fermentation effect was best when the agents' addition was one percent.

c) The relationship between corn powder added and fermentation effect: The addition of corn powder in processes 6,10 and 11 were respectively $0,0.5$ and $1 \%$. Table 2 shows that the content of crude protein in process 10 was increased by $12.92 \%$ than that in process 6 , the content of crude protein in process 11 was increased by $0.22 \%$ than that in process 10 . Why the second increase was not obvious was that $\mathrm{C} / \mathrm{N}$ played an important part in microbial growth and was one of main factors improving the content of crude protein. The crude protein of seaweed feed increased with the addition of 


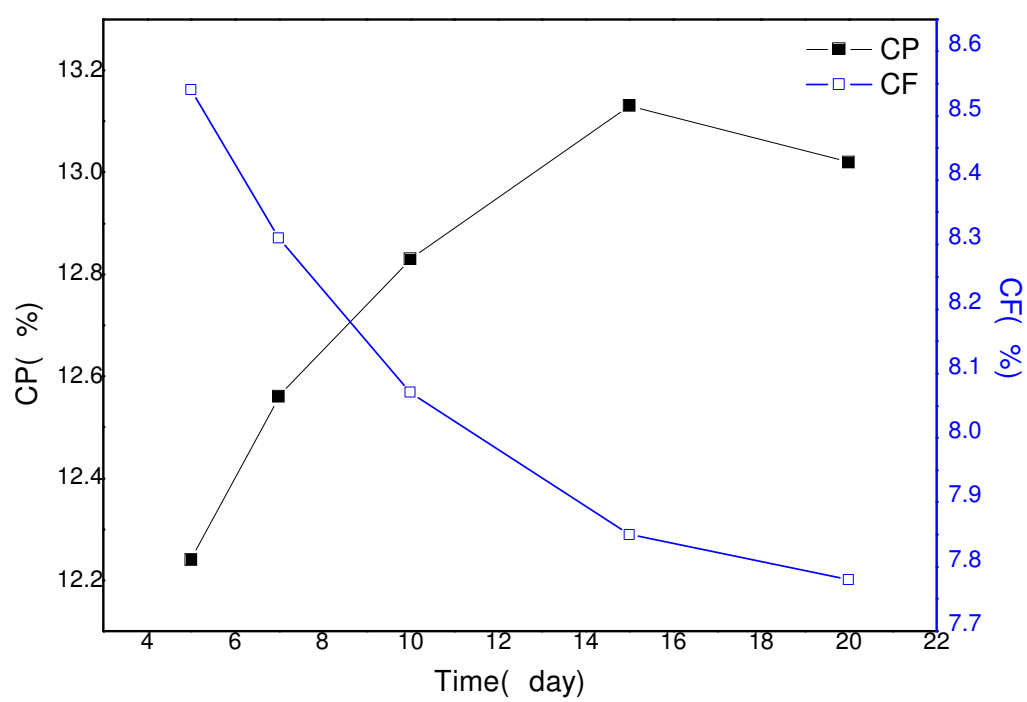

Figure 1. The relationship between the time and the content changes on $\mathrm{CP}$ and CF.

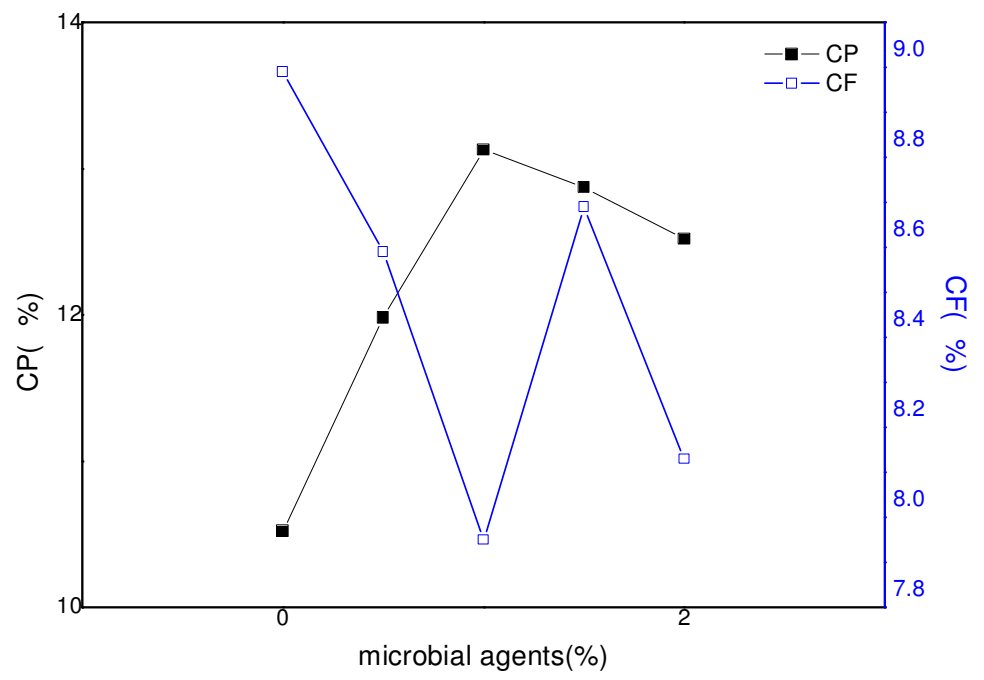

Figure 2. The relationship between the microbial agents coposition and the content of CP and CF.

corn powder. Additionally, the more the corn powder was added, the more the cost of the fermentation was. So the most favorable addition was $0.5 \%$.

\section{Conclusions}

In summary, the three factors containing fermentation time, microbial agents and corn powder had an effect on the fermentative effect. Experiments showed that seaweed feed was the best when $1 \%$ of microbial agents and $0.5 \%$ of corn powder were added, fermenting for 15 days, which was the tenth process. Compared with seaweed waste, the crude protein of seaweed feed increased by $34.56 \%$ and the crude fiber decreased by $10.72 \%$. Feed is the basis material for the development of animal husbandry and aquaculture. With the rapid development of animal husbandry, the demand of feed is increasing. On the contrary, the amount of cultivated land has dropped drastically. Therefore, it is much more imperative to search for the unconventional feed such as seaweed waste feed replacing the conventional feed such as corn, wheat, soybeans and so on. Compared with the conventional feed such as corn straw, cassava cane, turnip leaf and wild grass, the seaweed feed is much richer in crude protein, crude fiber and minerals which are 


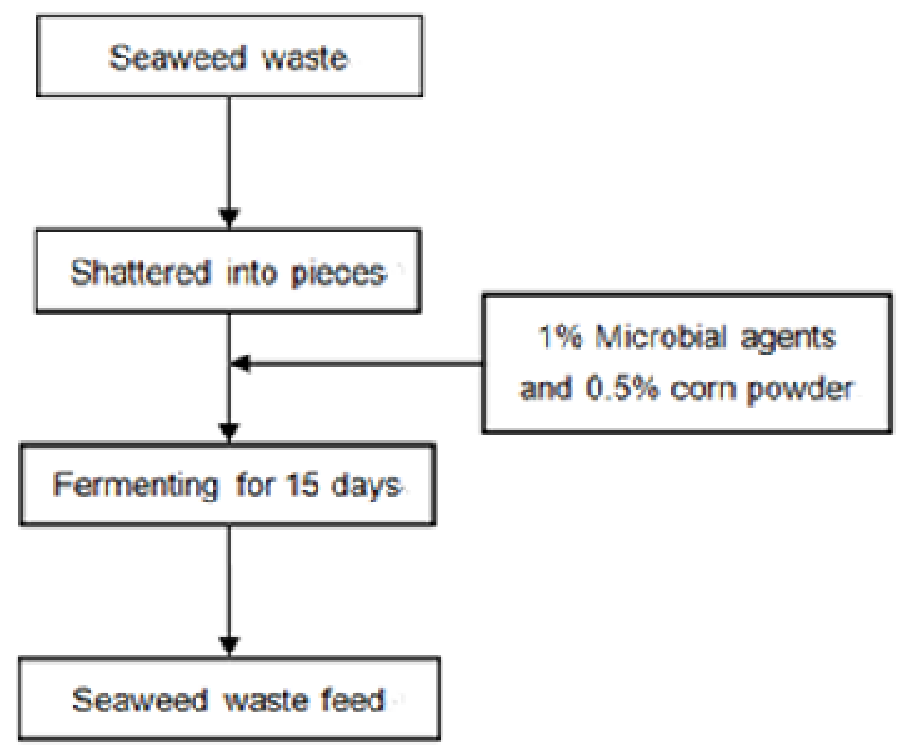

Figure 3. The flow diagram of seaweed waste fermented process.

Table 3. The main components of seaweed in China.

\begin{tabular}{lclc}
\hline Chemical composition & Content & Chemical composition & Content \\
\hline Energy (MJ/kg) & 1.045 & Glutamic acid (\%) & 0.38 \\
Ash (\%) & $20-35$ & Threonine $(\%)$ & 0.18 \\
Crude protein (\%) & $6-8$ & Lysine $(\%)$ & 0.10 \\
Crude fiber (\%) & $8-11$ & Methionine $(\%)$ & 0.28 \\
Crude fat (\%) & $0.1-0.15$ & Potassium $(\mathrm{mg} / \mathrm{kg})$ & 4.30 \\
Mannitol (\%) & $14-21$ & Sodium $(\mathrm{mg} / \mathrm{kg})$ & 3.24 \\
Algin $(\%)$ & $20-24$ & Magnesium $(\mathrm{mg} / \mathrm{kg})$ & 0.50 \\
Laminaran $(\%)$ & 1.7 & Strontium $(\mathrm{mg} / \mathrm{kg})$ & 0.05 \\
Fucose $(\%)$ & 0.3 & lodine $(\mathrm{mg} / \mathrm{kg})$ & $4000-7000$ \\
Carotene $(\mathrm{mg} / \mathrm{kg})$ & $6-10$ & Calcium $(\mathrm{mg} / \mathrm{kg})$ & 0.07 \\
Vitamin E $(\mathrm{mg} / \mathrm{kg})$ & 7.21 & Phosphorus $(\mathrm{mg} / \mathrm{kg})$ & 0.16 \\
Oryzanin $(\mathrm{mg} / \mathrm{kg})$ & $>0.09$ & Manganese $(\mathrm{mg} / \mathrm{kg})$ & 37.0 \\
Lactochrome $(\mathrm{mg} / \mathrm{kg})$ & $0.36-0.50$ & Zinc $(\mathrm{mg} / \mathrm{kg})$ & 139.0 \\
Nicotinic acid $(\mathrm{mg} / \mathrm{kg})$ & 16 & Cuprum $(\mathrm{mg} / \mathrm{kg})$ & 20.0 \\
Linoleic acid $(\mathrm{mg} / \mathrm{kg})$ & 0.2 & Moisture $(\%)$ & $<14$ \\
\hline
\end{tabular}

beneficial to the growth and reproduction of domestic animals. At the same time, fermented feed from Seaweed waste not only can handle a large number of wastes generated in the seaweed industry and reduce environmental pollution, but also alleviate the problem of feed shortage which will bring considerable economic benefits.

\section{ACKNOWLEDGMENTS}

This work was financially supported by the Key Projects in the National Science and Technology Pillar Program during the Eleventh Five-year (2007BA62B04), Yangtze River Delta Joint research project (0939581140) and Shanghai international cooperation projects (073458014). This paper was supported by "Shanghai-Unilever Research and Development Fund" 08540750500, projects 09395811400, S2012C000005 and 11395803100.

\section{REFERENCES}

Cheng ZX, Yin YB, Zhang Q, Huang GF (2003). Effect on feeding with kelp meal on the growth performance of weaned piglets. Heilongjiang J. Ani. Sci. Vet. Med. 8:21-22. 
Gan CJ, Shi SY, Shi MT (1999). Status and Perspective of Comprehensive Utilization of Laminaria Industrial Wastes. Adv. Environ. Sci. $7(1): 50-53$.

Gao RJ, Song GT, Wang SJ (2004). Experiments of the Effect of New Algae Acid Fertilizer. Shandong Agric. Sci. 3:62-66.

$\mathrm{Li} \mathrm{ZH,} \mathrm{He} \mathrm{S,} \mathrm{Gao} \mathrm{HD} \mathrm{(2007).} \mathrm{Research} \mathrm{on} \mathrm{seaweed} \mathrm{feed} \mathrm{at} \mathrm{pre-}$ sent.China Anim. Health, 6:65-66.

Liu JX, Yang ZH, Ye JA (1999). The rational allocation of silage feed and feed evaluation standard. Feed Industry. 4:3-5.

Lu JJ, Li TY, Zhang Y, Xiao KY, Xia ZS (2010). Study on characteristic of straw feed fermentated by Sporocytophaga, bacillus subtilis and yeast. Feed China. 41:47-49.

Wang P, Yang WR, Yang ZB, Jiang SZ, Zhang GG (2009). Effect on the performance of growing pigs while adding kelp residue in the dietary. Feed Rev. 6:40-41.

Yang HY, Cui ZJ (2005). Feed addition fermentated with corn straw and its research progress. Anim. Husb. Vet. Med. 37(6):5.

Yang S (1993). Feed analysis and feed quality testing technology. Beijig: China Agricultural University Press. pp.85-97.
Yu LJ (2006). Fermentation engineering principles and technology. Beijig: Chemical Industry Press. pp.155-195.

Zeng LH, Cheng F (2004). Recent advance in the application of natural plant as feed additives. Southwest China J. Agric. Sci.17(2):257-261.

Zhang G, Zheng R (2000). Study on corn straw feed fermentated with multi-strain. Acta Agric. Boreali-sin. S1:175-177. 